\title{
PECULIARITIES OF SINGLE TRACK FORMATION FROM TI6AL4V ALLOY AT DIFFERENT LASER POWER DENSITIES BY SELECTIVE LASER MELTING\#
}

\author{
I. Yadroitsava ${ }^{1}$, J. Els ${ }^{2}$, G. Booysen ${ }^{3} \&$ I. Yadroitsev ${ }^{4}$ \\ Department of Mechanical and Mechatronic Engineering \\ Central University of Technology, Free State, South Africa \\ 1iyadroitsava@cut.ac.za, ${ }^{2}$ jels@cut.ac.za, ${ }^{3}$ gbooysen@cut.ac.za, ${ }^{4}$ iyadroitsau@cut.ac.za
}

\begin{abstract}
This paper describes the geometrical characteristics of single tracks manufactured by selective laser melting (SLM) at different laser powers (20-170 W) and scanning speeds (0.1$2.0 \mathrm{~m} / \mathrm{s}$ ). Simulation of temperature distribution during processing is carried out. A conclusion about the optimal process parameters and peculiarities of selective laser melting of Ti6Al4V alloy at low and high laser powers and scanning speeds is reached. The analysis of temperature fields creates opportunities to build parts with the desired properties by using SLM.
\end{abstract}

\section{OPSOMMING}

Hierdie artikel beskryf die geometriese karakterisering van enkel bane wat deur selektiewe laser smelting (SLS) teen verskillende laser energievlakke (20-170 W) en skandering snelhede $(0.1-2.0 \mathrm{~m} / \mathrm{s})$ vervaardig is. ' $\mathrm{n}$ Simulasie van temperatuurverspreiding gedurende prosessering is uitgevoer. Gevolgtrekkings aangaande die optimale proses parameters en kenmerkende eienskappe van SLS van Ti6Al4V teen lae en hoë laser krag en skandering spoed is uitgevoer. Ontleding van temperatuurvelde skep geleenthede om onderdele met gewenste eienskappe te vervaardig deur middel van SLS.

\# This article is an extension of a paper presented at the $15^{\text {th }}$ Annual International RAPDASA conference held in Stellenbosch, South Africa in November 2014.

2 The author is enrolled for an MSc degree in the Department of Mechanical and Mechatronic Engineering, Central University of Technology, Free State.

* Corresponding author 
Selective laser melting (SLM) is a highly suitable technology for the fabrication of complex objects with fine structures in one working cycle. Selective laser melting is sometimes called 'direct metal 3D printing' [1]. It emphasises the simplicity and elegance of the idea of adding powder material during the manufacturing process. In fact, selective laser melting of powders is a very complex and costly process. SLM is a multi-disciplinary technology based on optics, laser physics, heat and mass transfer, metallurgy, mechanics, and other fields of science. Laser-powder-substrate interactions, heat conduction and convection processes, and fluid flow and evaporation make this process extremely difficult to control and analyse. The SLM part - with the desired geometry - is created by solidifying track-by-track and layer-by-layer. The properties of parts produced by this technology depend on the geometrical characteristics of each single track, the morphology of each layer, and the cohesion of tracks and layers. Changing only one process parameter or powder property (for example, particle size distribution or chemical composition) may cause porosity or cracks in the $3 \mathrm{D}$ object. Since temperature gradient and heat transfer determine the microstructure and final mechanical properties of the SLM part, studies of temperature distribution during SLM are of primary importance.

Titanium alloys have grown in popularity in the manufacturing industry in recent years, mainly due to their unique properties such as high strength, low density, corrosion resistance, high operating temperatures, and biocompatibility. Ti6Al4V alloy is known as the most commonly-used $\alpha-B$ titanium alloy. The microstructure and mechanical properties of as-built SLM parts depend on material properties, process parameters, scanning strategy, and even part geometry. Most of the work with titanium alloys is devoted to the study of the properties of SLM objects retrieved as a whole, without an analysis of single tracks [25]. The effect of laser power and scanning speed on the morphology of single tracks from loose titanium powder was studied by Kyogoku et al. [6]. Continuous tracks were formed at laser power 30-40 W with spot size $170 \mu \mathrm{m}$ at scanning speed $0.005-0.01 \mathrm{~m} / \mathrm{s}$. The width of the track was about $450 \mu \mathrm{m}$ at an energy density of $10-40 \mathrm{~J} / \mathrm{mm}^{2}$. It should be noted that melting of powder material preplaced to the substrate will dramatically change the geometrical characteristics of the tracks, due to the changing thermo-physical conditions of the joint melting of powder and substrate. A variation in process parameters causes change in the geometry and shape of single tracks. The study of single tracks and maximal temperature can help to avoid porosity in 3D objects. It also allows for the selection of an optimal manufacturing strategy for fully dense objects or lattice structures [7]. Analysis of temperature fields at different process parameters creates opportunities to build parts with the desired properties using SLM.

The aims of this work were i) to study the shape and geometrical characteristics of SLM single tracks manufactured with different laser power densities and scanning speeds on the Ti6Al4V substrate; ii) to simulate temperature distribution and compare it with experimental values of maximal temperature; iii) to analyse the peculiarities of SLM of Ti6Al4V alloy at low and high laser powers and scanning speeds; and iv) to select optimal process-parameters for SLM of Ti6Al4V powder.

\section{MATERIALS AND METHODS}

Ti6Al4V supplied by TLS Technik $\mathrm{GmbH}$ is a pre-alloyed gas-atomised powder with the following nominal chemical composition: $\mathrm{Ti}$ - balance, $5.84 \mathrm{Al}, 4.21 \mathrm{~V}, 0.004 \mathrm{C}, 0.042 \mathrm{Fe}$, $0.0860,0.005 \mathrm{~N}, 0.002 \mathrm{H}$ (wt. \%). The substrate and the powder material were similar in chemical composition. Powder particles have high sphericity and smooth surfaces; sieve diameters weighted by volume were $d_{10}=12.6 \mu \mathrm{m}, d_{50}=29.8 \mu \mathrm{m}$ and $d_{90}=41.5 \mu \mathrm{m}$. Argon was used as a protective gas. SLM experiments were carried out by two methods. 1) An SLM machine from Phenix Systems using single-mode continuous-wave Ytterbium fibre laser operating at $1075 \mathrm{~nm}$ wavelength (IPG Photonics Corp.) with $2 r_{0}=70 \mu \mathrm{m}$ spot size. Laser powers were 20, 30, and 50 W. 2) EOSINT M270 (EOS GmbH.) equipped the same type of 
laser with a $100 \mu \mathrm{m}$ spot diameter. Laser powers were set between 150 and $170 \mathrm{~W}$. Laser beams had a $\mathrm{TEM}_{00}$ Gaussian profile. Cross-sections of the samples were subjected to grinding with $320 \mathrm{SiC}$ paper, and then polishing by diamond suspension ( $9 \mu \mathrm{m}$ size) and with Silica $(0.05 \mu \mathrm{m}$ size). Cross-sections of the samples were etched in Kroll's reagent. A 3D numerical simulation was carried out using a Comsol (COMSOL, Inc.) 'Heat Transfer in Solids' module.

To estimate the temperature fields during SLM, numerical simulations were conducted. In order to obtain accurate results, the density of the mesh in the region around the irradiation, and on the top region of the sample $(100 \mu \mathrm{m})$, was higher than in the sample as a whole, with the minimal mesh size at $0.1 \mu \mathrm{m}$. The laser beam with Gaussian profile scanned along the $X$-axis at the surface of the solid sample. The evolution of the temperature due to heat conduction was:

$\rho c_{p} \frac{\partial T}{\partial t}-\nabla(k \nabla T)=P(1-R) \frac{A_{z}}{\pi r_{0}^{2}} e^{-\frac{(x-V t)^{2}+y^{2}}{r_{0}^{2}}} e^{-A_{z} z}$

$T$ is the temperature; $t$ is the time; $\rho$ is the density of material; $c_{p}$ is the specific heat capacity; $k$ is the thermal conductivity; $P$ is the laser power; $R$ is the surface reflectivity of material for given wavelength; $A_{z}$ is the coefficient of absorption; $r_{0}$ is the characteristic radius of the laser beam; $x, y, z$ are dimensional values; and $V$ is the laser scanning speed. Equation (1) takes into consideration only the effect of conduction into the solid [8].

Numerical simulation of single tracks during SLM of Ti6Al4V was conducted by Song et al. [9] using a $34 \mu \mathrm{m}$ laser beam diameter, $0.2 \mathrm{~m} / \mathrm{s}$ scanning speed, and $110 \mathrm{~W}$ laser power $\left(121.2 \mathrm{~kW} / \mathrm{mm}^{2}\right)$. Temperature-dependent thermal conductivity and specific heat capacity were introduced for $293-923 \mathrm{~K}$. The calculated maximal temperature on the surface of Ti6Al4V was about $6,500^{\circ} \mathrm{C}$. The maximum temperature of molten Ti6Al4V substrate versus irradiation time and laser power was experimentally measured by Yadroitsev et al. [10]. At 20-50 W laser power, $70 \mu \mathrm{m}$ spot diameter, and scanning speed $0.1-0.3 \mathrm{~m} / \mathrm{s}$ (5.2$13.0 \mathrm{~kW} / \mathrm{mm}^{2}$ ), the maximum temperature did not exceed $3,000 \mathrm{~K}$.

For the present study, all the properties of the material were temperature-dependent [1113]. To validate the model, the actual experimental parameters were used as input for the simulation. Effective thermal conductivity of the liquid metal was introduced, and was multiplied by a factor of 1.5-3, taking into account heat transfer due to flows. Apart from the top surface, all other boundaries were assumed to be thermally insulated. The heat flux on the top surface simulates convective cooling. Heat loss due to convection is expressed by:

$q_{c}=h_{c}\left(T-T_{0}\right)$

where $T_{0}=293 \mathrm{~K}$ is the initial temperature, and $h_{c}=10 \mathrm{~W} /\left(\mathrm{m}^{2} \mathrm{~K}\right)$ is the convection coefficient.

\section{$3 \quad$ RESULTS AND DISCUSSION}

\subsection{Laser melting of bulk material}

Laser welding is closest to the SLM process in physics, and has been studied more. According to Rońda and Siwek [14], laser welding can take place via two routes: - the conduction or keyhole modes - depending on the power density of the laser beam $\left(P / \pi r_{0}^{2}\right)$. At low power density, heat transport follows the conduction mode. With high power density - i.e. high laser power and small spot size - the keyhole mode can develop. The Gaussian laser beam has spatial intensity distribution, and the resulting temperature fields are not uniform across the molten pool. The temperature is highest at the centre and lowest at the edges of the molten pool. The surface tension gradient - due to the high temperature 
gradient on the surface - can set up a recirculating flow within the molten pool, and this thermocapillary convection changes the physics of the process [15]. Because of the recirculating flow, the pool shape changes. The difference is found to be quite significant: an increase of up to 1.5 times in the width/depth ratio compared with pure conduction. It was found that an increase in the Marangoni number, which depends on temperature gradient, increases the aspect ratio. Marangoni flow, density gradients, and thermal expansion of the material have an influence on the shape of the molten pool. With the increase of laser power, the temperature gradient is more pronounced, causing a higher Marangoni flow and waves in the liquid. After rapid solidification, the resulting track has deformations. Kou et al. [16] have shown that the oscillatory Marangoni flow in the weld pool can provoke pool-surface deformation, pool-surface oscillation, and ripple formation.

Laser power density, as a ratio of the laser power to laser spot size, and time of irradiation (i.e. scanning speed) play a significant role in the geometry and shape of the molten pool. Laser power density defines the temperature gradient, and the scanning speed determines the time of laser-matter interaction $(t)$. For 20-50 W laser power with $70 \mu \mathrm{m}$ spot diameter, neither humping effects nor keyhole modes were found for $t=0.2-0.7 \mathrm{~ms}$. For this range of laser power, $5.2-13.0 \mathrm{~kW} / \mathrm{mm}^{2}$ power density resulted in a conductive mode of laser processing Ti6Al4V substrate. The keyhole mode causes material to evaporate from the laser interaction region, leading to the creation of a deep and narrow molten pool. 150-170 W laser power caused very deep molten pools at $0.6 \mathrm{~m} / \mathrm{s},(t=0.17 \mathrm{~ms}$, laser power density was 19.1-21.7 kW/ $\mathrm{mm}^{2}$ ) (Figure 1).

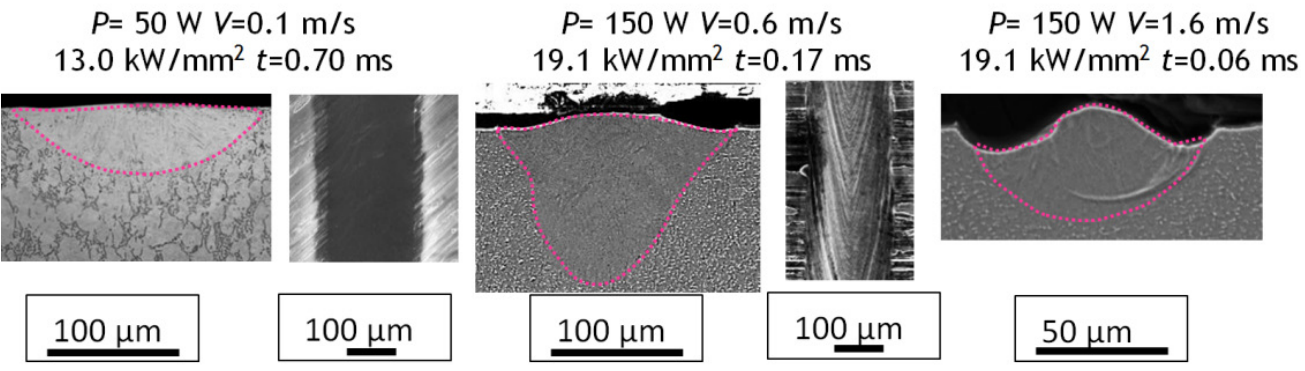

Figure 1: Cross-sections and top view and of the single tracks on Ti6Al4V substrate (please see online version for colour image)

Tracks produced by 20-50 W laser power had light convexity in the middle due to surface tension, and possibly due to phase transformation and the volume changing in the remelted zone and base material. The influence of the laser power on the width of the track was more pronounced than that of the scanning speed: the width of the track with an increase in laser power from 20 to $50 \mathrm{~W}$ increased about 185 per cent for the same scanning speed, while it decreased 135-140 per cent with the scanning speed $(0.1-0.3 \mathrm{~m} / \mathrm{s})$ within the same laser power (Figure 2). Re-melted depth with an increase in laser power from 20 to $50 \mathrm{~W}$ became deeper by 2.1-2.2 times. With faster laser scanning of $0.3 \mathrm{~m} / \mathrm{s}$, it was shallower by $1.5-1.6$ times compared with $0.1 \mathrm{~m} / \mathrm{s}$.

The morphology of the single tracks fabricated at 150-170 $\mathrm{W}$ changed with the scanning speed. Ripples on the top surface were in an elongated and pointed form. At $1.6 \mathrm{~m} / \mathrm{s}$ and higher scanning speeds, tracks had a pronounced rising in the centre like the humping mode in welding (Figure 1). Yang et al. [17] also presented cross-sections of the single track with wave top surface at the Ti6Al4V plate sample processed with a laser scanning speed of $0.01735 \mathrm{~m} / \mathrm{s}$ and laser power of $678 \mathrm{~W}$ with a $4.4 \mathrm{~mm}$ laser spot size $\left(8.88 \mathrm{~J} / \mathrm{mm}^{2}\right)$. Thus, in laser melting with high power density, fluid flows and convection strongly affect the shape and geometry of the resulting track. The hydrodynamics of the melt pool are complicated by different regimes of laser scanning [18]. Geometrical characteristics, the volume of the molten pool, and the temperature gradient can cause instability of the molten pool. Rippling and humping were determined by the formation of a capillary wave on the free 
liquid surface. Under surface tension, the pressure differences created at the curve interface support deformation of the interface. High temperature provoked a decrease in viscosity; therefore the hydrodynamics of the melt pool became more pronounced at a higher temperature.

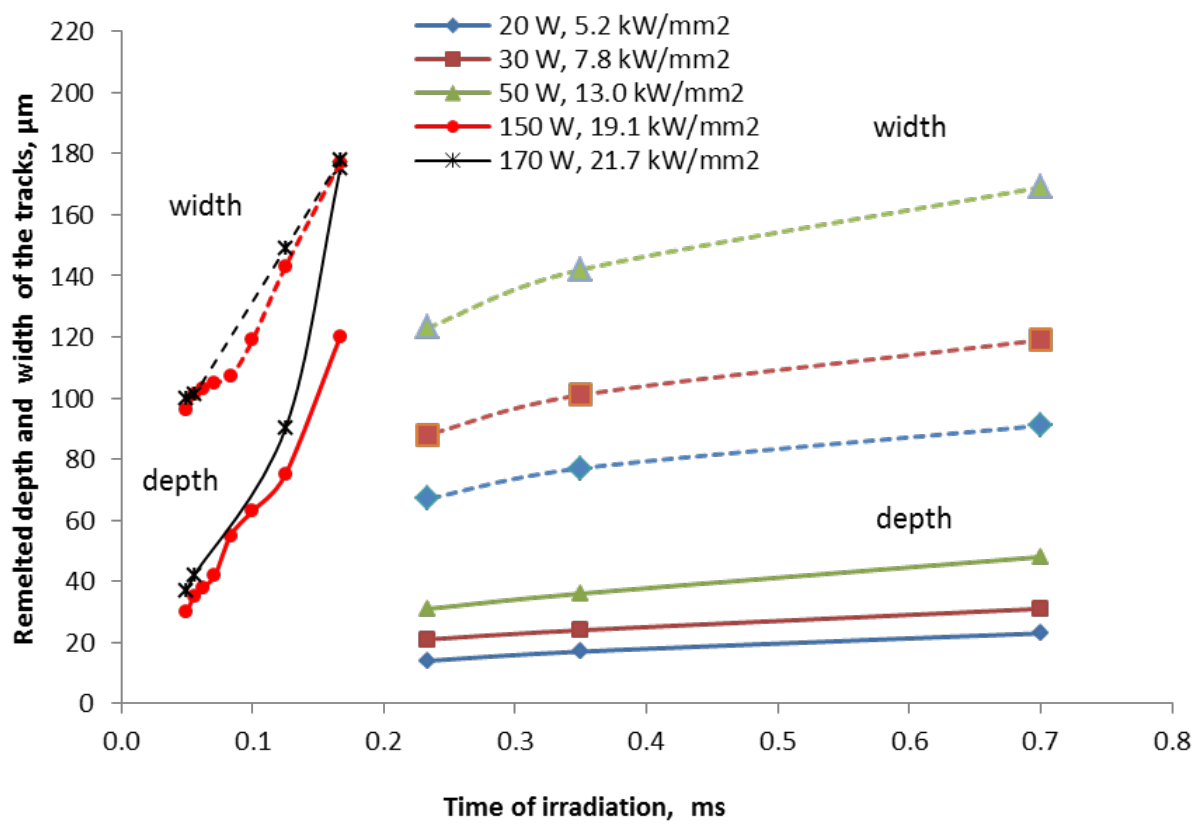

Figure 2: Remelted depth and width of the tracks produced at different laser power densities on Ti6Al4V substrate. The dashed lines are the widths of the tracks, and the solid lines are re-melted depth. Power density is the ratio of laser power to area of laser spot $\left(P /\left(\pi r_{0}^{2}\right)\right)$. Time of irradiation is $2 r_{0} / V$. (please see online version for colour image)

Wei [19] has indicated the following mechanisms of instability of the melt pool: difference in velocities between gas and liquid; density gradients; Rayleigh capillary instability due to capillary pressure difference; solute super saturation; surface tension gradient (Marangoni effect); evaporation pressure difference; the occurrence of hydraulic jump if the pressure gradient becomes increasingly adverse as the flow proceeds downstream; laser polarisations; gravitational-electromagnetic instability; and interactions between gravitational and electromagnetic forces. For SLM, the most important are Rayleigh capillary and thermocapillary instabilities and evaporation.

Numerical simulations have shown that the geometrical size of the molten pool changes with scanning speed: the length of the melt pool becomes longer and shallower (Figure 3). The 150-170 W laser power isotherms had an elongated pointed form as ripples on the top surface of experimental tracks.

\subsection{Laser melting of powder}

The geometrical characteristics of the tracks produced from powder depend strongly on the volume of material involved in the process (Figure 4). At high scanning speeds the track width remained nearly constant, approaching the size of the laser beam diameter. For $45 \mu \mathrm{m}$ powder layer variability in the track width was higher due to irregularities in the powder layer delivered on the substrate (Figure 4a). Track height is primarily determined by the thickness of the deposited powder layer and its apparent density. For stable tracks at $15 \mu \mathrm{m}$ layer thickness the heights of tracks were about 5-10 $\mu \mathrm{m}$, and for $30 \mu \mathrm{m}$ it was 10 $18 \mu \mathrm{m}$; for $45 \mu \mathrm{m}$ it was $12-32 \mu \mathrm{m}$. At $170 \mathrm{~W}$ laser power, the height of the tracks was lower than ones produced by $150 \mathrm{~W}$ laser power, but the width of the tracks produced by $170 \mathrm{~W}$ 
was slightly greater (Figure 4b). Inhomogeneity of the deposited layer and melt hydrodynamics made the height of the tracks vary greatly. At low scanning speeds, a 'keyhole' shape of the molten pool and deep penetration into the substrate were observed. At $170 \mathrm{~W}$ re-melted depth was higher for all scanning ranges, and the difference in the depth for 15 and $30 \mu \mathrm{m}$ layers was less pronounced (Figure 4c). For $45 \mu \mathrm{m}$ layer thickness it varied strongly with scanning speed. The re-melted depth is one of the decisive factors for manufacturing SLM objects with mechanical properties, such as wrought materials, so layer thickness may be critical for good layer cohesion. High input energy for high laser power and slow scanning speeds leads to evaporation and a deep molten pool. Remelting each laser pass about $160 \mu \mathrm{m}$ in depth (more than 15 layers, if shrinkage during powder melting is taken into account) as it passes at $150 \mathrm{~W}$ laser power for $30 \mu \mathrm{m}$ powder layer and $0.6 \mathrm{~m} / \mathrm{s}$ scanning speed, is very unproductive and costly. Keyhole mode and evaporation also can provoke porosity (Figure $4 \mathrm{~d}$ ). For $45 \mu \mathrm{m}$ powder layer, a balling effect starts at scanning speeds above $1.4 \mathrm{~m} / \mathrm{s}$. Therefore, a range of scanning speeds $\left(\Delta V_{\text {opt }}\right) 0.8-1.2 \mathrm{~m} / \mathrm{s}$ is optimal for 15-45 $\mu \mathrm{m}$ powder layer and laser power 150-170 W.
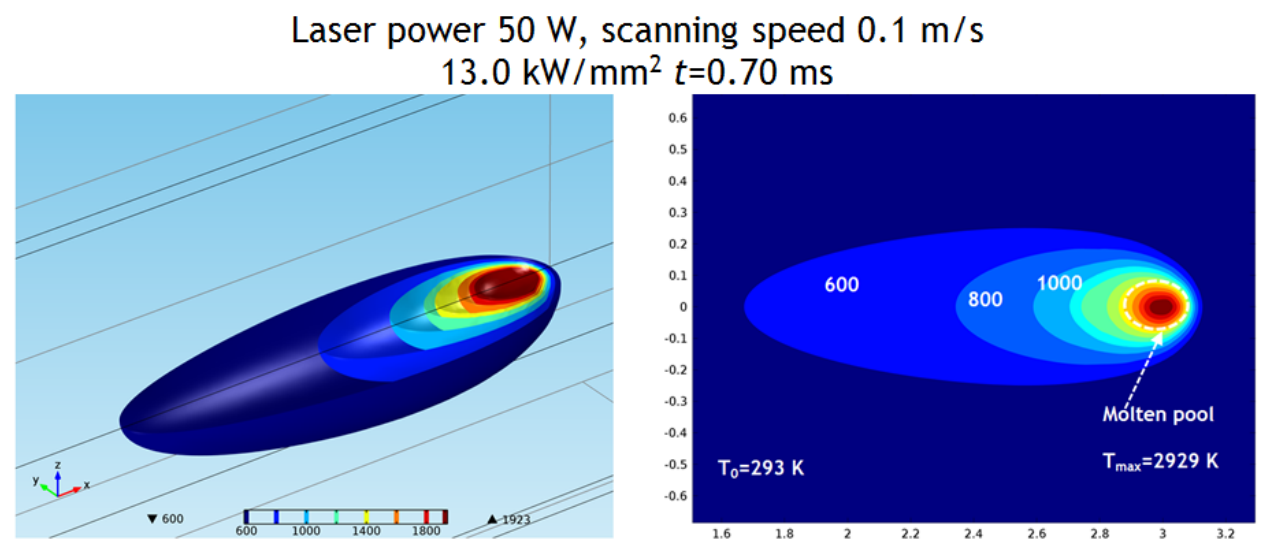

Laser power $150 \mathrm{~W}$, scanning speed $1.0 \mathrm{~m} / \mathrm{s}$

$19.1 \mathrm{~kW} / \mathrm{mm}^{2} \mathrm{t}=0.1 \mathrm{~ms}$
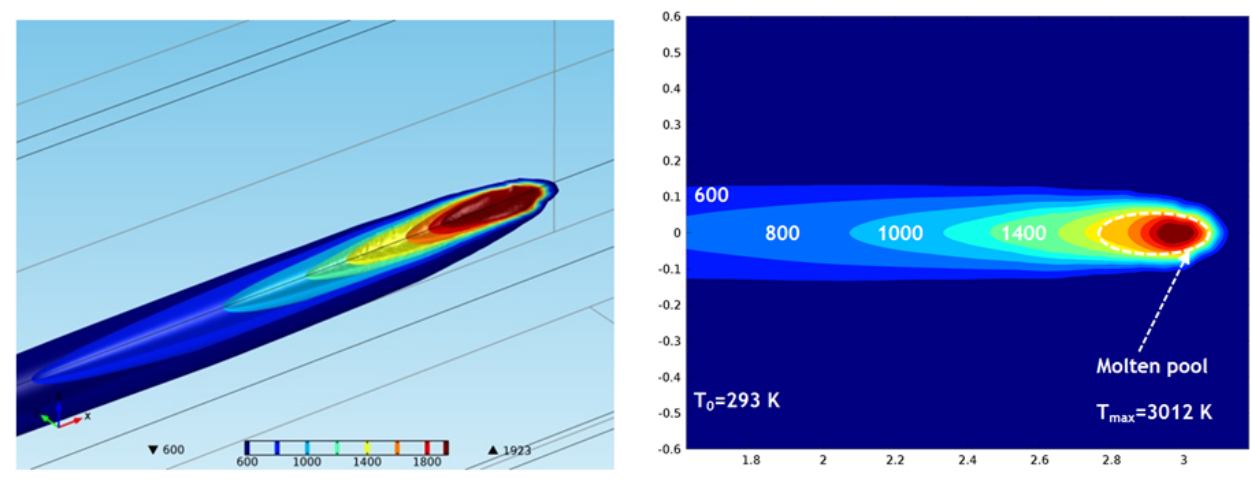

Figure 3: Results of numerical simulation of laser melting of Ti6Al4V substrate. Isothermal contours for different laser power and scanning speeds. (please see online version for colour image) 


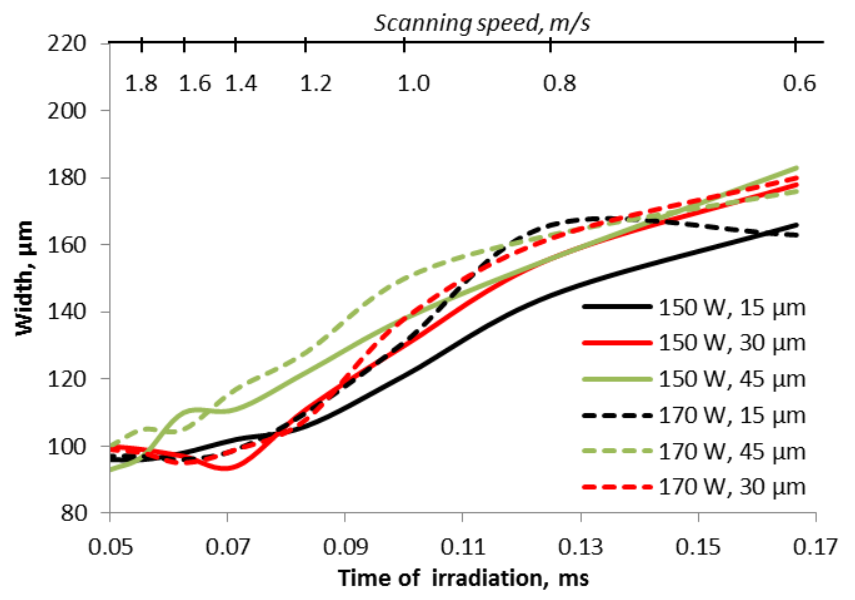

(a)

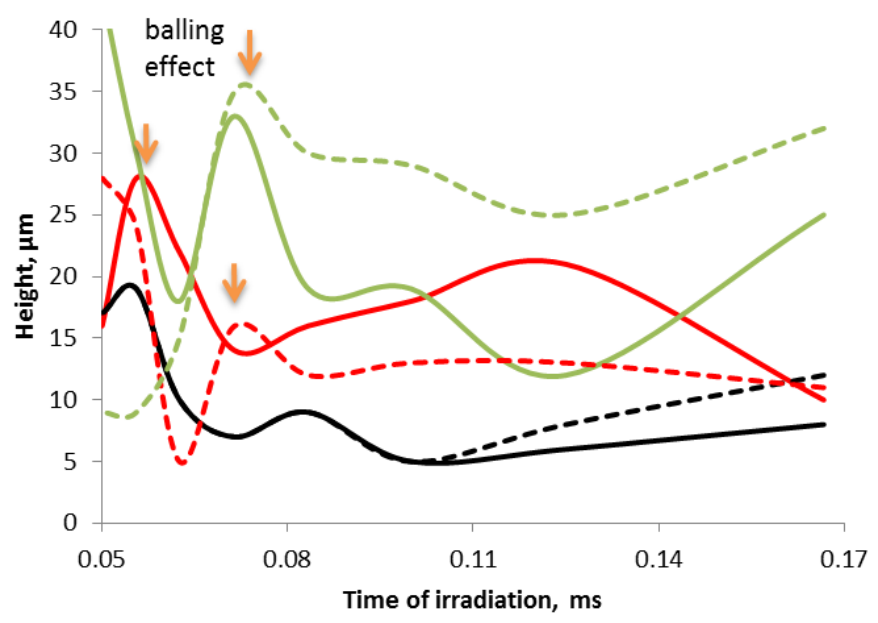

(b)

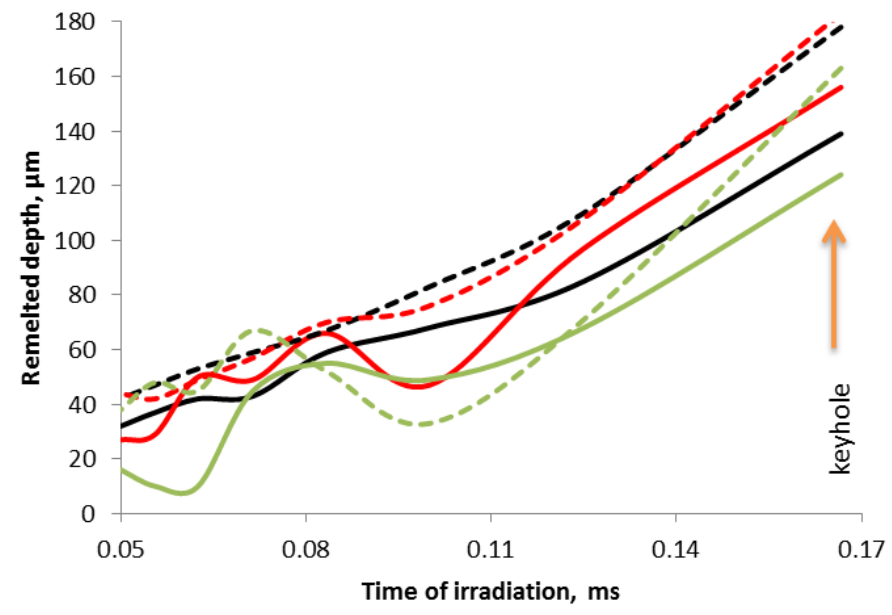

(c)

Figure 4(a-c): Geometrical characteristics (please see online version for colour images) 


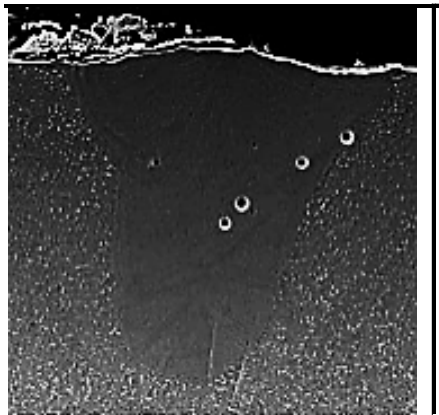

$P=150 \mathrm{~W}$

$V=0.6 \mathrm{~m} / \mathrm{s}$

$h=30 \mu \mathrm{m}$

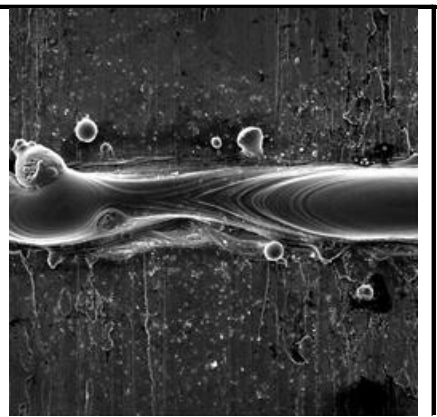

$P=150 \mathrm{~W}$

$V=1.6 \mathrm{~m} / \mathrm{s}$,

$h=45 \mu \mathrm{m}$

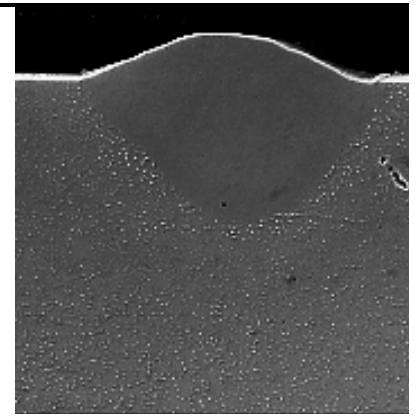

$P=170 \mathrm{~W}$

$V=0.8 \mathrm{~m} / \mathrm{s}$,

$h=45 \mu \mathrm{m}$

(d)

Figure 4d: Cross-section and top view of single tracks from Ti6Al4V powder

Yadroitsev et al. [20] have shown that penetration into the substrate can provide an additional stabilising effect for the manufacturing of continuous single tracks, because the segmental cylinder is more stable than the free circular one. It was suggested that the range of the optimal scanning speed $\left(\Delta V_{\text {opt }}\right)$ will be larger for higher laser power. For metallic powder processing with 20-50 W laser power and $50 \mu \mathrm{m}$ powder layer, the optimal range for scanning speeds was about $\Delta V_{\text {opt }}=0.1 \mathrm{~m} / \mathrm{s}$. Using $150-170 \mathrm{~W}$, the optimal range of scanning speeds expanded to $\Delta V_{\text {opt }}=0.4 \mathrm{~m} / \mathrm{s}$ for powder layer thickness $15-45 \mu \mathrm{m}$.

Laser power density is one of the main parameters in selective laser melting. The conductive mode of SLM at low power density cannot generate keyhole, only irregular tracks at low scanning speeds or balling-effect at high scanning speeds. Rescanning of the sintered layer can help to avoid porosity in 3D SLM objects produced at low power densities. Using high laser density provokes keyhole at low scanning speeds. Also, a balling effect is observed for high laser power density and high scanning speed. Rescanning may not help to eliminate the porosity, because gas bubbles can be locked in very deep layers in the keyhole mode. Elaboration of adequate power and speed for rescanning is quite difficult in this case. For high laser density, the humping effect and ripples in the tracks form a layer with complex morphology. When the next layer of the powder is deposited on the previous very rough synthesized layer, non-homogeneity leads to different thermophysical conditions of the scanning. The newly-synthesised tracks will have different geometric characteristics, and their superposition will form a single layer with a different morphology from the previous layer.

Laser power density is the ratio of laser power to the laser spot area. Increasing the laser spot size can stabilize the SLM process up to the conductive mode. But there is another subtle point. Since the width of the laser spot size determines the width of the track (spot diameter can be up to several millimetres for lasers with high power), it is clear that using a high power laser in SLM can produce only near-shape objects or only solid core parts without thin walls or complex fine structures. But the application of high-power lasers with a big spot size increases the builfd rate of SLM. Thus, selective laser melting due to nonlinear behaviour laser beam-powder/substrate material is always a compromise between productivity and accuracy.

\section{CONCLUSION}

The geometrical characteristics of SLM single tracks manufactured at different laser power densities and scanning speeds on the Ti6Al4V substrate were studied. The results of simulations of maximal temperature for laser scanning of the substrate agreed well with the experimental data. The conduction model with temperature-dependent properties is useful for the estimation size of molten pool and temperature fields during SLM. Selective 
laser melting of Ti6Al4V alloy at low and high laser power densities has some peculiarities. Using high power laser density allows an increased scanning speed and powder layer thickness, which is positive for the affectivity and productivity of this additive manufacturing technology. From the other hand, high power laser density can lead to very deep penetration and evaporation of the material, or to the production of a shallow and long molten bath, which results in the instability of the molten pool and a balling effect. Keyhole pores, or pores provoked by the balling effect, will degrade the quality of the SLM object. During the selection of the optimal scanning strategy and process parameters (laser power density, scanning speed, hatch distance, and thickness of powder layer), not only the width, height and re-melted depth of the tracks, but also the morphology of the tracks has to be considered.

To manufacture regular and continuous single tracks, each power density has its own range of optimal scanning speeds at different powder layer thicknesses. Studying how these tracks form layers using different scanning strategies, and how to produce overhanging parts and parts with inclination angles and lattice structures, is the real task. Dynamically changed process parameters during manufacture can be used to sinter different parts of complex objects, not just for the contouring procedure of the whole SLM object. Thus the optimal process parameters for 3D SLM objects with the desired characteristics have to be chosen, taking into consideration the peculiarities of this technology. Temperature fields defining thermal cycling, microstructure, and the properties of the final 3D objects are the subject of much contemporary research in the field of SLM.

\section{ACKNOWLEDGEMENTS}

This work is based on research supported by the South African Research Chairs Initiative of the Department of Science and Technology and National Research Foundation of South Africa (Grant №97994) and the Collaborative Programme in Additive Manufacturing (Contract № CSIR-NLC-CPAM-15-MOA-CUT-01).

\section{REFERENCES}

[1] 3D Systems.com. http://www.3dsystems.com/files/direct-metal-brochure-0214-usen-web.pdf.

[2] Murr, L.E., Quinones, S.A., Gaytan, S.M., Lopez, M.I., Rodela, A., Martinez, E.Y., Hernandez, D.H., Martinez, E., Medina, F. \& Wicker, R.B. 2009. Microstructure and mechanical behavior of Ti-6Al-4V produced by rapid-layer manufacturing, for biomedical applications. Journal of the Mechanical Behavior of Biomedical Materials, 2, pp 20-32.

[3] Thijs, L., Verhaeghe, F., Craeghs, T., Van Humbeeck, J. \& Kruth, J.-P. 2010. A study of the microstructural evolution during selective laser melting of Ti-6Al-4V. Acta Materialia, 58, pp 3303-3312.

[4] Ramosoeu, M.E., Chikwanda, H.K., Bolokang, A.S., Booysen, G. \& Ngonda, T.N. 2010. Additive manufacturing: Characterization of TI-6Al-4V alloy intended for biomedical application. Light Metals Conference, The Southern African Institute of Mining and Metallurgy Advanced Metals Initiative, pp 337-344.

[5] Simonelli, M., Tse Y.Y. \& Tuck, C. 2012. Microstructure of Ti-6Al-4V produced by selective laser melting. Journal of Physics: Conference Series, 371, pp 012-084.

[6] Kyogoku, H., Shimizu, Y. \& Yoshikawa, K. 2013. Surface morphology of selective laser-melted titanium. International Solid Freeform Fabrication Symposium. Austin, Texas, pp 846-852.

[7] Yadroitsev, I. 2009. Selective laser melting: Direct manufacturing of 3D-objects by selective laser melting of metal powders. Lambert Academic Publishing GmbH \& Co.

[8] Sanders, D.J. 1984. Temperature distributions produced by scanning Gaussian laser beams. Applied Optics, 23(1), pp 30-35.

[9] Song, B., Dong, S., Liao, H. \& Coddet, C. 2012. Process parameter selection for selective laser melting of Ti6Al4V based on temperature distribution simulation and experimental sintering. The International Journal of Advanced Manufacturing Technology, 61, pp 967-974.

[10] Yadroitsev, I., Krakhmalev, P. \& Yadroitsava, I. 2014. Selective laser melting of Ti6Al4V alloy for biomedical applications: Temperature monitoring and microstructural evolution. Journal of Alloys and Compounds, 583, pp 404-409.

[11] Hodge, N.E., Ferencz, R.M. \& Solberg J.M. 2014. Implementation of a thermo-mechanical model for the simulation of selective laser melting. Computational Mechanics, DOI $10.1007 / \mathrm{s} 00466-014-1024-2$. 
[12] Mills, K.C. 2002. Recommended values of thermophysical properties for selected commercial alloys. ASM International, Cambridge, England.

[13] Boivineau, M., Cagran, C., Doytier, D., Eyraud, V., Nadal, M.-H., Wilthan, B. \& Pottlacher, G. 2006. Thermophysical properties of solid and liquid Ti-6Al-4V alloy. International Journal of Thermophysics, 27(2), pp 507-529.

[14] Rońda, J. \& Siwek, A. 2011. Modelling of laser welding process in the phase of keyhole formation. Archives of Civil and Mechanical Engineering, 3, pp 739-752.

[15] Chan, C.L., Mazumder, J. \& Chen, M.M. 1987. 3-dimensional axisymmetric model for convection in laser-melted pools. Materials Science and Technology, 3, pp 306-311.

[16] Kou, S., Limmaneevichitr, C. \& Wei, P.S. 2011. Oscillatory Marangoni flow: A fundamental study by conduction-mode laser spot welding. Welding Journal, pp 229-240.

[17] Yang, J., Sun, S., Brandt, M. \& Yan, W. 2010. Experimental investigation and 3D finite element prediction of the heat affected zone during laser assisted machining of Ti6Al4V alloy. Journal of Materials Processing Technology, 210, pp 2215-2222.

[18] Fabbro, R. 2010. Melt pool and keyhole behaviour analysis for deep penetration laser welding. Journal of Physics D: Applied Physics 43(44), pp 445-501.

[19] Wei, P.S. 2012. The physics of weld bead defects. In: Welding processes, ed. R.Kovacevic, InTech DOI: $10.5772 / 2884$, pp 395-414.

[20] Yadroitsev, I., Gusarov, A., Yadroitsava, I. \& Smurov, I. 2010. Single track formation in selective laser melting of metal powders. Journal of Materials Processing Technology, 210 (12), pp 1624-1631. 